sow, Ziwolka, and Moisseew (1832-39), and a few notes by Höfer and Nordenskiöld, and from his own observations, Grinewetaky gives the following sketch of the south island of Novaia Zemlia. It may be divided into three parts. The northern lies between Matotschkin Shar on the north and the Pukowaja River on the south: this part has the highest mountains (four thousand feet), forming isolated groups rather than ranges. The central part, extending to the Karelka and Belushia Rivers, has five or six parallel ridges, running generally north and south; black slate is common; and the watershed is about seventeen miles from the west coast. The southern part is a rather low plateau: the Goose Land (Gusiwaya Zemlia) is included in this part, which is free from snow by the end of June, and in July has a rather rich vegetation, especially on the gently sloping ground.

Dr. Grinewetzky also expressed the opinion that the wild reindeer of the northern island belong to a totally distinct sub-species from those of the southern island.

\section{LOSS OF NITROGEN FROM ARABLE SOILS.}

THE renewed attention of agriculturists has of late been drawn to the question of the nitrogen supply of cultivated soils. On the one hand, Schulz, in Germiny, claims to have brought about a gain of nitrogen on a sandy soil by means of the cultivation of lupines, and manuring with kainit. On the other hand, Lawes, Gilbert, and Warington, ${ }^{1}$ in England, have published results which show that a very considerable annual loss of nitrogen occurs in the drain-water of cultivated fields; and experiments by Dehérain, ${ }^{2}$ in France, show, according to his interpretation of them, an alarming decrease in the total nitrogen of the soil in the course of a few years, and in spite of abundant manuring.

Schulz's experiments have added nothing to our knowledge of the natural supply of nitrogen to the soil, and it is not proposed to consider that topic here. The results of Lawes, Gilbert, and Warington, and of Dehérain, however, have attracted much attention. If they are to be accepted without reserve, they lead to the conclusion that the fertility of our cultivated fields, so far as it depends upon their nitrogen, is being removed in the drainage-water, or in other ways, at a comparatively rapid rate.

The instigation to Lawes, Gilbert, and Warington's experiments was given by the observation, that, in the field-experiments carried on for a series of years at Rothamsted, scarcely a third of the nitrogen of the manure was found in the crop under the most favorable conditions, while, in those cases in which no mineral manures were applied, the deficit was much greater. The most obvious conclusion was, that there must be a great loss of nitrogen in the drainage; and experiments were instituted to test this idea. Their earlier experiments were with three lysimeters. Excavations were made under and around an area of

\footnotetext{
1 Journ. roy. agric. soc., xvij. and xviii.

2 Annales agronomique, viii. 321.
}

a thousandth of an acre. The mass of soil thus isolated was supported by perforated iron plates, and surrounded by masonry, thus leaving the soil with its natural structure. The quantity of water percolating through this soil has been determined since 1870 ; and since May, 1877, its content of nitrates has been also determined. The soil was uncultivated and free from vegetation. Numerous interesting facts are disclosed by these determinations, but that which now interests us chiefly is the quantity of nitrogen found in the drain-water. This amounted, in the average of four years, to 46,36 , and 44 pounds per acre, at depths respectively of 20,40 , and 60 inches.

Subsequently the same experimenters have determined the nitrates in the drainage-waters from their experimental wheat-field, each plot of which is drained by a single lateral at a depth of 24 to 30 inches. Having no means of measuring the drainage, the authors take, as the basis of their calculation of the loss of nitrogen, the amount of drainage-water yielded by the 60-inch deep lysimeter at the same time. On this assumption, the annual loss of nitrogen varied from 15 and 16 pounds per acre, on unmanured plots, to as high as 74 pounds per acre.

It is greatly to be regretted that the authors were not able to measure the drain-water in these experiments; for the method which was adopted to supply the deficiency leaves much to be desired. The soil in the lysimeter was uncultivated and bare of vegetation: that of the wheat-field was cultivated, and bore crops of wheat varying considerably in amount. Both these circumstances affect the amount of drainage-water. Cultivation, especially of a clay soil such as that at Rothamsted, may affect very markedly the ease with which water passes downward through it, the amount of water which it can retain in its interstices, and the rapidity of evaporation from its surface. The growth of vegetation exerts a still greater effect on the movements of water in the soil. It has been shown by numerous observers, that much more water evaporates from a soil covered with vegetation than from a bare soil, and that cousequently much less of the rainfall percolates through the soil. The diminution of the drainage-water in this way has also been directly proved by Wollny. Furthermore, the various plots in these experiments carried unequal quantities of vegetation, so that the amount of evaporation due to this source must have been unequal also. It appears, then, in the highest degree improbable, that the quantity of drainage-water actually was the same for each plot as was assumed, and unlikely that it was as great as was assumed. When we add to these considerations the fact, that it is uncertain whether the soil of the lysimeter represented an average of the soil of the field, and, further, that all errors of the lysimeter are multiplied a thousandfold when the results are expressed per acre, we are forced to the conclusion that the figures given for the total amount of drain-water, and consequently those also for the total loss of nitrogen in this way, can be, at best, only approximations, and are most likely too large. 
Even if we allow them their full value, however, they do not in all cases cover the entire loss of nitrogen. On the basis of the results just described, the authors have calculated the average annual amount of nitrogen in the manure, crop, and drainage of fourteen experimental wheat-plots for a period of thirty years. In seven cases the nitrogen found in crop and drainage is from 14 to 40 pounds per acre less than the amount applied as manure. Analyses of the soil of one plot in 1865, and again in 1881, showed that about a third of this amount was still present in the soil, the latter having gained nitrogen. The authors believe the remainder either to have escaped the drain-tiles, and been carried into the lower strata of the soil, or to have been set free in the gaseous state in the soil.

Dehérain's experiments were intended to determine the total loss of nitrogen by the soil. Three series, of four plots each, were laid out, each plot having an area of one are (equal to about four'square rods). 'The first series bore fodder-maize; the second, potatoes; the third, beets, fodder-maize, and esparcette successively. During the first three years, one plot in each series was unmanured; one received, per hectare, 80,000 kilograms of stable-manure; one, 1,200 kilograms of nitrate of soda; and one, 1,200 kilograms of sulphate of ammonia. During the following four years none of the plots received any manure. At the beginning of the experiments, and at the end of three and seven years respectively, the percentage of nitrogen in the soil was determined. With the aid of these determinations, a balance was struck for each plot between the nitrogen originally present and that added in the manure, on the one hand, and that removed in the ciops and remaining in the soil at the close of the experiments, on the other hand. In every case except that of the esparcette, a very great loss of nitrogen was found to have occurred. The following table contains the annual loss of nitrogen from a portion of the plots, reduced to pounds per acre to compare with Lawes, Gilbert, and Warington's results:-

\begin{tabular}{|c|c|c|c|}
\hline Manuring. & & First period. & Second period. \\
\hline 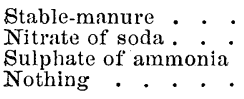 & 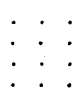 & $\begin{array}{l}-257 \\
-358 \\
-320 \\
-338\end{array}$ & $\begin{array}{r}-118 \\
-183 \\
-132 \\
-\quad 93\end{array}$ \\
\hline
\end{tabular}

Esparcette plots.

\begin{tabular}{|c|c|c|}
\hline Manuring. & $\begin{array}{l}\text { First period } \\
\text { (roots and } \\
\text { maize). }\end{array}$ & $\begin{array}{l}\text { Second period } \\
\text { (esparcette). }\end{array}$ \\
\hline 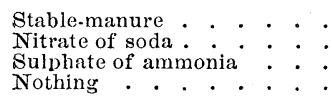 & $\begin{array}{l}-808 \\
-663 \\
-732 \\
-567\end{array}$ & $\begin{array}{l}+327 \\
+134 \\
+135 \\
+149\end{array}$ \\
\hline
\end{tabular}

Compared with the losses observed in Rothamsted, some of these figures are enormous, being over nine times as great as the highest obtained there. When we consider that the soil was calculated to contain, to a depth of 14 inches, only about 7,000 pounds of nitrogen per acre, they seem to show that but a comparatively short time would be required to reduce the supply of nitrogen to the point at which culture ceases to be profitable.

In order to be able to judge of the force of these results, it is desirable, in the first place, to consider somewhat more in detail the method by which they were obtained. At the beginning of the experiments the soil was found to contain .204\% of nitrogen; and this was made the basis of the calculation for all the plots. It is highly improbable that this assumption of uniformity among all the plots, as regards nitrogen, is correct; and, when we consider that a difference of $.001 \%$ corresponds to a difference of about 34 pounds of nitrogen per acre, we are led to question, not only the accuracy of Deherain's results, but the possibility of discovering small losses of nitrogen by means of soil-analysis. 'The absolute quantity of nitrogen was calculated on the further assumption that one hectare of soil to a depth of 35 centimetres weighed $3,850,000$ kilograms, which, again, involves a possibility of error. Finally, the determination of the quantity of nitrogen removed in the weighed crops rests on assumptions as to the percentage of nitrogen they contained, while it is a well-established fact that considerable variations in this respect occur. Especially does heavy manuring with nitrogenous fertilizers, such as some of these plots received, tend to increase the percentage of nitrogen in the crop.

To recapitulate: Dehérain's conelusions involve three improbable assumptions; viz, , pertect uniformity of soil as regards nitrogen, equal weight of soil over equal areas, and a uniform and average percentage of nitrogen in the crops.

On the other hand, all but a few of the plots show a loss of nitrogen; and while, for the reasons just stated, the accuracy of the reults is very questionable, it would appear that we must admit some loss of nitrogen to be probable in most of the experiments.

Aside from these considerations, however, there are others which should be borne in mind. During the first three years the manured plots were very heavily manured. Sulphate of ammonia and nitrate of soda were applied at the rate of 1,070 pounds per acre, and stable-manure at the rate of over $35 \frac{1}{2}$ tons per acre, quantities much greater than would be used under any ordinary conditions. Moreover, from the fact that the unmanured plots yielded nearly as large crops at the close of the experiments as at their beginning, we may conclude that the soil was naturally of good quality.

Dehérain's calculations show that but a very small proportion of the nitrogen of the manures was utilized by the crops; and, though the exactitude of his figures may be questioned, the general result is what we should expect. A large excess of available nitrogen was evidently present in the soil. The latter was occupied by crops for only four or five months of the year, at most (except the esparcette plots); and, during the remaining two-thirds of the year, leaching, and other 
natural agencies which tend to remove nitrogen from the soil, had undisputed possession of the field. When the manuring was discontinued, the losses of nitrogen, according to Dehérain's results, sank very materially, though still remaining considerable.

From the combined results of both these investigations, it would appear that we may fairly conclude, that, under ordinary conditions of tillage, there is considerable loss of nitrogen from the soil. Lawes, Gilbert, and Warington's experiments show that much nitrogen may escape in the drainage; and, according to their calculations, more nitrogen was removed from six out of thirteen of their experimental plots in crop and drainage, during thirty years, than was supplied in the manure. From Dehérain's experiments we learn that a soil under constant tillage may grow poorer in nitrogen in spite of heavy manuring. In fact, of all the elements of the soil which are required for plant-growth, nitrogen is one of the most mobile. The soil, it is true, has the power of fixing ammonia in insoluble combinations; but both ammonia and organic nitrogen are constantly being converted into nitric acid in every fertile soil, and this compound the soil has no power to retain. Under natural conditions, when the soil is thickly covered with vegetation, this nitric acid is assimilated by the roots as rapidly as it is forined, while the compact state of the soil hinders access of oxygen to the deeper layers, and thus moderates nitrification. This action of plantroots in arresting nitrates on their way to the lower strata of the soil is shown very plainly in Lawes, Gilbert, and Warington's experiments already cited. While the land carried a crop of wheat, the drain-water contained little or no nitrates, except when an excess of nitrogen had been given in the manure; but as soon as the crop was removed, nitrates made their appearance in the drain-water.

But an untilled soil is not only protected against losses of nitrogen: it is also in condition to retain the nitrogen brought to it in rain, snow, etc. This comes partly in the form of ammonia, which is fixed by the soil, and partly in the form of nitric acid, which is fixed by the vegetation. In this way a soil carrying permanent vegetation may be continually gaining nitrogen. This is indicated by Dehérain's results on the esparcette plots, and, aside from them, is sufficiently evident from the facts, that at some period of the world's history all its nitrogen must have existed in the free state, and that, so far as we know, the combined nitrogen of atmospheric precipitates is the sole natural source of nitrogen to the soil.

Tillage alters this state of things very materially. By breaking up and mellowing the soil, it facilitates the access of oxygen, and increases the rapidity of nitrification. At the same time, the natural vegetation is replaced by one occupying in many cases but a part of the ground, and occupying it for but a portion of the year. Add to this that by diminishing the amount of vegetation we diminish the evaporation of water, and thus leave the soil moister, and at the same time expose it more fully to the sun's rays, thus rendering it warmer, both of which conditions favor nitrification, and we see that cultivation both increases the flux of nitrogen in the soil, and decreases the means of utilizing it.

The clear recognition of this state of things brings with it the suggestion of at least a partial remedy, which is to keep the soil occupied as fully and as long as possible with growing vegetation. The roots of the living plant lend to the soil an absorptive power for nitrogen compounds, similar to that which it has of itself for other elements of plant-food, and enable it. to store up these compounds against future needs. To prevent a loss of nitrogen, we must make use of this power as fully as possible, both in the system of cultivation adopted, and in other ways. After taking off a crop in the early fall, instead of leaving the land bare, let it be sown with some quick-growing crop, e.g., lye, which shall serve solely to store up the nitrogen which would otherwise be lost. In the spring this crop is ploughed under, and furnishes nourishment for the succeeding crop. Such a plan has been adopted here and there with adyantage. Its general use would turn largely, of course, on the question of expense. On a virgin soil containing already large reserves of nitrogen, no appreciable benefit might result from it, though even there the preservation of the present fertility is worth striving for. But between this condition and the state of relative exhaustion to which the soil of our older states has been reduced, there must be a point where saving nitrogen in this way would be of immediate as well as prospective benefit. The exact methods of applying the principle involved to particular cases it is not the province of this article to discuss. The principle itself, however, is very simple. Keep growing roots present in the soil as long and as extensively as possible to seize upon the nitrogen (and other elements as well) which will otherwise be washed out of the soil, and to store it up in insoluble forms, ready for the needs of future crops.

H. P. ARMsby.

\section{THE LIFE OF HAMILTON.}

Life of Sir William Rowan Hamilton, Knt., LL.D., D.C.L., M.R.I.A., Andrews professor of astronomy in the University of Dublin, and royal astronomer of Ireland, etc. : including selections from his poems, correspondence, and miscellaneous writings. By Robert Perceval Graves, M.A., sub-dean of the Chapel royal, Dublin. Vol. i. London, Longmans, Green, \& Co., $1882.20+698$ p. $8^{\circ}$.

THIs volume, which forms one of the latest issues of the Dublin university press series, has been prepared partly through the assistance furnished by the Board of 'Trinity college, and published by the provost and senior fellows. $\mathrm{Mr}$. Graves had at first, however, undertaken the biography of Hamilton on his own responsibility, and unassisted in the labor which it involved; and we ought not to pass unremarked his especial fitness for the performance of this arduous task. In the first place, he was unconnected with Hamilton by 